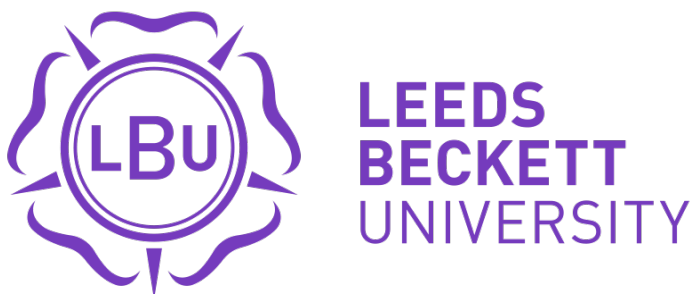

Citation:

Sewry, N and Lambert, M and Roode, B and Matthews, B and Hendricks, MS (2016) The velocity of ball-carriers and tacklers during shoulder tackles. International Journal of Performance Analysis in Sport, 16 (2). pp. 486-497. ISSN 1474-8185

Link to Leeds Beckett Repository record:

https://eprints.leedsbeckett.ac.uk/id/eprint/3021/

Document Version:

Article (Accepted Version)

The aim of the Leeds Beckett Repository is to provide open access to our research, as required by funder policies and permitted by publishers and copyright law.

The Leeds Beckett repository holds a wide range of publications, each of which has been checked for copyright and the relevant embargo period has been applied by the Research Services team.

We operate on a standard take-down policy. If you are the author or publisher of an output and you would like it removed from the repository, please contact us and we will investigate on a case-by-case basis.

Each thesis in the repository has been cleared where necessary by the author for third party copyright. If you would like a thesis to be removed from the repository or believe there is an issue with copyright, please contact us on openaccess@leedsbeckett.ac.uk and we will investigate on a case-by-case basis. 


\title{
The Velocity of Ball-Carriers and Tacklers during Shoulder Tackles
}

\author{
Nicola Sewry ${ }^{1}$ \\ Mike Lambert ${ }^{1}$ \\ Brad Roode ${ }^{1}$ \\ Bevan Matthews ${ }^{1}$ \\ Sharief Hendricks ${ }^{1}$ \\ ${ }^{1}$ MRC/UCT Research Unit for Exercise Science and Sports Medicine University of \\ Cape Town
}

\begin{abstract}
A major characteristic of rugby union is that of the tackle, with the shoulder tackle occurred most frequently. The tackle is the facet of rugby most associated with injury incidence. Owing to this, and the lack of research, the velocities involved with the shoulder tackle were investigated. Twelve shoulder tackles were selected and the velocity of the ball-carrier and tackler were determined using a $2 D$ analysis tool applied to commercial video footage. The tackles were coded according to pass number, match period, quality of defence and attack, match status, defensive shape and movement, position of tackler and ball-carrier. Using ANOVA, the association between the variables and the velocity were determined. The ball-carrier's velocity $\left(4.10 \pm 1.85 m^{-1} 1\right)$ when entering contact was significantly higher than the tackler's velocity $\left(5.19 \pm 3.22 \mathrm{m.s}{ }^{-1}\right)$. The ballcarrier's velocity was significantly higher when entering contact further from the set piece $(p<0.001)$, when playing away from home $(p<0.001)$ and when ranked in the top three teams in the competition $(p<0.001)$. The ball-carrier's velocity significantly decreased when facing a tight forward in contact $(p<0.05)$. The tackler's velocity was significantly slower in the $3^{\text {rd }}$ match period $(40-60 \mathrm{~min})(p<0.05)$ compared to the other match periods.
\end{abstract}

Key Words : velocity, shoulder tackle, rugby union 
The Velocity of Ball-Carriers and Tacklers during Shoulder Tackles

\author{
Abstract \\ Key Words
}




\section{Introduction}

A major characteristic of rugby union is that of intentional frequent bodily collisions known as the tackle(Duthie, Pyne, and Hooper, 2003). The tackle is a dynamic phase of play when compared to other phases such as the scrum. The player's ability to effectively engage in the tackle contest has been associated, in part, to the outcome of the match(Vaz, van Rooyen, and Sampaio, 2010). Furthermore, the tackle has been associated with the highest incidence of injury compared to any other facet of play(Fuller, Ashton, Brooks, Cancea, Hall, and Kemp, 2010). Tackles can be classified according to the direction from which the ball-carrier is contacted by the tackler (for example front-on and side-on) and described by the manner by which contact is made (for example arm tackle, shoulder tackle and smother tackle)(Fuller, Ashton, Brooks, Cancea, Hall, and Kemp, 2010).

The most common occurring tackle in a rugby union match is the shoulder tackle(Hendricks, Matthews, Roode, and Lambert, 2014; McIntosh, Savage, McCrory, Frechede, and Wolfe, 2010), because if executed correctly, is the most safe and effective. With the shoulder tackle recommended (both for safety and effectiveness)(Australian Rugby Union, 2008; Hendricks and Lambert, 2010; New Zealand Rugby Union, 2007) it has become a particular interest of research. In match situations, McIntosh, Savage, McCrory, Frechede and Wolfe (2010)(McIntosh, Savage, McCrory, Frechede, and Wolfe, 2010) have showed a positive association with the level of play and the proportion of active shoulder tackles. Within a lab and controlled field setting, Usman, McIntosh and Frechede (2011)(Usman, McIntosh, and Frechede, 2011) have attempted to quantify the forces involved with shoulder tackles and associate them with factors such as experience and player position.

The velocities at which the ball-carrier and tackler enter the tackle is hypothesized to be a contributing factor for injury and success in the tackle(Garraway, Lee, Macleod, Telfer, Deary, and Murray, 1998; Headey, Brooks, and Kemp, 2007; Hendricks, Karpul, Nicolls, and Lambert, 2012; Kaplan, Goodwillie, Strauss, and Rosen, 2008; McIntosh, Savage, McCrory, Frechede, and Wolfe, 2010; Quarrie and Hopkins, 2008). Hendricks et al. measured the velocity of the ball-carrier and tackler 0.5 seconds before front-on tackles, and reported an average velocity of approximately $5 \mathrm{~m} . \mathrm{s}$ for the ball-carrier and $5.7 \mathrm{~m} . \mathrm{s}$ for the tackler across 3 different levels of play(Hendricks, Karpul, Nicolls, and Lambert, 2012). Based on their findings, the authors suggested that when tacklers enter the pre-tackle phase (i.e 0.5 seconds) at a velocity considerably different to that of the ball-carrier (whether higher or lower), tacklers adjust their velocity accordingly to reach a suitable relative velocity before making contact with the ball-carrier(Hendricks, Karpul, Nicolls, and Lambert, 2012). Indeed, this insight has proved meaningful in understanding the dynamics of the tackle in real match situations(Hendricks, Karpul, Nicolls, and Lambert, 2012). With that said, the velocity at which the ball-carrier and tackler enters the contact situation is mostly likely governed by the match situation(Hendricks, Matthews, Roode, and Lambert, 2014; Hendricks, Roode, Matthews, and Lambert, 2013), and not much known in this regard. A better understanding of contact dynamics will allow for better training prescription and 
coaching. Therefore, the aim of this study was to investigate the factors that affect the velocity of the tackler and ball-carrier in shoulder tackles in the Super 14 rugby union competition.

\section{Methods}

Fifteen matches publically televised matches from the 2010 Super 14 rugby tournament were analysed for this study. Although the matches were selected at random, quota sampling was used to ensure relatively equal distribution of instances within teams and competition weeks. This was used to avoid a bias towards a specific team or competition week. From the 15 matches, 763 instances where the defence and attack, and the resultant tackle could be identified were coded. Defence was defined as the team not in possession of the ball, with two or more players (defenders) facing the attacking line at the phase of play or at the point of breakdown. An attacking line was identified when the ball-carrier (attacker in possession of the ball) and potential ball-carriers (attackers in proximity) challenged the gain line(Sayers and Washington-King, 2005). A tackle was defined 'when the ball-carrier was contacted (hit and/or held) by an opponent (tackler) without reference to whether the ball-carrier went to ground(Fuller, Ashton, Brooks, Cancea, Hall, and Kemp, 2010). Of the 763 instances, only 12 front-on shoulder tackles that met the visibility criteria (described below) were subsequently used for velocity before tackle contact analysis. Video footage was analysed using Sports Code elite version 6.5.1, using an Apple iMac (Apple, USA) positioned at eye level. The analysis software allowed control over the time lapse during each movement, and the recording and saving of each coded instance into a database. During the analysis, the analyst was at liberty to pause, rewind and watch the footage in slow motion. The highest frequency at which the analyst could slow down the motion of the footage was $25 \mathrm{~Hz}$ (25 frames per second).

\subsection{Velocity measurement}

The velocity measurement for this study is described elsewhere(Hendricks, Karpul, and Lambert, 2012; Hendricks, Karpul, Nicolls, and Lambert, 2012). In brief, the video footage of the tackle event had to fulfill the following visibility criteria i) Visual of 4 locations with known distances represented by the lines on the field, ii) Clear running path for at least 0.5 seconds of the ball-carrier and primary tackler pre-tackle, iii) Camera had to remain fixed over this period. Tackle events that fulfilled these criteria subsequently imported into Dartfish Team- pro (Version 4.0.9.0 Switzerland). Using Dartfish Analyser, a timer was set to zero at the point of contact between the ball-carrier and primary tackler. The ball-carrier and tackler were then retracted for 0.5 seconds ( 25 frames) from the point of contact. This period is considered the pre-tackle phase(Fuller, Ashton, Brooks, Cancea, Hall, and Kemp, 2010). Thereafter, the ball-carrier and tackler were tracked forward to the point of contact for the 0.5 seconds. Ball-carriers were generally tracked from mid- section 
(hip area) and tacklers on the upper body. The rationale for this is that during most tackles, tacklers enter the tackle with their upper body as the first point of contact. Once the body region was selected, the tracking of the player was meticulously observed to confirm that the tracked path was indeed the movement path of the body region in question (i.e. mid-section for ball- carriers and upper body for tacklers), as the tracking software may be confounded by elements such as similar playing kit colours to opposition, video footage clarity, surrounding players etc. In cases where the tracking software lost the selected point on the player, and deviated from the obvious movement path, the tracking software was returned to the point on the body and the tracking path re-established. A line was then drawn with the software through the tracked path of both the ball-carrier and tackler, and divided into 0.1 second intervals (Five 0.1 second intervals, six markings). An image of the analysed tackle, with the marked 0.1 seconds intervals, was subsequently imported into Matlab (Version 6.5, Mathworks Inc, United States of America).

An algorithm to determine the planar location of a single point determined by pixel co-ordinates within an image was developed in Matlab (Version 6.5, Mathworks Inc, United States of America). As mentioned earlier, one of the inclusion criteria for analysis of the tackle event was a visual of 4 locations with known distances represented by the lines on the field. This made it possible to enter four known $\mathrm{x}$ and y co-ordinates on the field. The program then created a 2D-axis (x; y) system in the plane of the field shown in the imported image from Dartfish. Once the 4 known coordinates were entered, and the 2D- axis system created, it was possible to obtain $\mathrm{x}$; y co-ordinates of any point on the field. To obtain the co-ordinates, the analyser had to simply select any point on the field, and the algorithm would calculate the coordinates despite the projective distortion to the image created by the camera (given that each tackle event was analysed individually and a scaled version of the field was reconstructed for each tackle event based on the visual and knowledge of distances between field markings, the projected distortion was accounted for). For every tackle event, a new image and a new 2D-axis system was created, according to the known distances. Before a tackle was analysed, and to further validate the 2Daxis system, co-ordinates produced by the $2 \mathrm{D}$-axis system had to correspond to the known distances of the playing field from the imported image.

The centre of the field (on the half-way line at the mid-point between the two touchlines) was chosen as the point of origin on the field $(x=0 ; y=0)$. After the additional validation, the co-ordinates of the marked 0.1 second intervals were obtained for both the ball-carrier and the tackler. The distance between 2 coordinates ( $\mathrm{x}$ and $\mathrm{y}$ ) was calculated and divided by 0.1 seconds to produce the average velocity $\left(\mathrm{m} . \mathrm{s}^{-1}\right)$ over that interval. This was repeated for the five 0.1 second intervals up to the point of contact for both ball-carrier and tackler. Average velocity over the 0.5 seconds was also calculated.

\subsection{Factors Variables}


For this study, pass number, match period, quality of defensive team, quality of attacking team, match status, defensive shape and movement, and ball-carrier and tackler position were used factors that may affect pre tackle contact velocity. Descriptions for each factor are provided in Table 1. 
Table 1: Descriptions of each variable coded.

\begin{tabular}{|c|c|c|}
\hline Operational Variable & & Descriptions \\
\hline \multicolumn{3}{|l|}{ Pass Number } \\
\hline & Immediate & $\begin{array}{l}\text { Attacker received possession of the ball directly from the } \\
\text { breakdown, or set piece. i.e. no pass }\end{array}$ \\
\hline & Close & $\begin{array}{l}\text { when the attacker received possession of the ball through no } \\
\text { more than one pass from the breakdown or set piece }\end{array}$ \\
\hline & Middle & $\begin{array}{l}\text { Attacker received possession of the ball through a pass from the } \\
\text { first receiver, i.e. second pass }\end{array}$ \\
\hline & Wide & $\begin{array}{l}\text { Attacker received possession of the ball through beyond the } \\
\text { second pass }\end{array}$ \\
\hline \multicolumn{3}{|l|}{ Match Period } \\
\hline & & $\begin{array}{l}\text { Each match was divided into four periods of } 20 \text { minutes } \\
\text { (1st,2nd ,3rd and 4th period) }\end{array}$ \\
\hline \multicolumn{3}{|c|}{ Quality of Defensive Team } \\
\hline & & $\begin{array}{l}\text { Defensive teams were divided into three groups top (1-4), } \\
\text { middle (5-9) and bottom (10-14) based on the final log } \\
\text { standings of the } 2010 \text { Super } 14 \text { tournament }\end{array}$ \\
\hline \multicolumn{3}{|c|}{ Quality of Attacking Team } \\
\hline & & $\begin{array}{l}\text { Attacking teams were divided into three groups top (1-4), } \\
\text { middle (5-9) and bottom (10-14) based on the final log } \\
\text { standings of the } 2010 \text { Super } 14 \text { tournament }\end{array}$ \\
\hline \multicolumn{3}{|l|}{ Match Status } \\
\hline & & $\begin{array}{l}\text { Whether the defensive team was winning, drawing or losing } \\
\text { during that instance coded }\end{array}$ \\
\hline \multicolumn{3}{|c|}{ Defensive Shape and Movement } \\
\hline & Up and In & $\begin{array}{l}\text { Defenders approach the attacking line in a straight-line } \\
\text { formation followed by the outer players (players furthest away } \\
\text { from the ball) advancing ahead of the line towards the ball }\end{array}$ \\
\hline & Up and Out & $\begin{array}{l}\text { Defenders approach the attacking line in a straight-line } \\
\text { formation followed by inner players (players closest to the ball) } \\
\text { following the movement of the ball towards the touchline }\end{array}$ \\
\hline & Push/rush & $\begin{array}{l}\text { Defenders approach the attacking line at a fast speed and are in } \\
\text { a straight and direct line }\end{array}$ \\
\hline & Lateral Shift & $\begin{array}{l}\text { Initial movement of the defenders is towards the touchline } \\
\text { without challenging attacking line/attacker }\end{array}$ \\
\hline & Rabbit Runner & $\begin{array}{l}\text { One defender shoots rapidly from the defensive line towards } \\
\text { attacking line/attacker }\end{array}$ \\
\hline & Straight Line & $\begin{array}{l}\text { Defenders are in a straight line while approaching the attacking } \\
\text { line }\end{array}$ \\
\hline
\end{tabular}




\begin{tabular}{|c|c|}
\hline Static Line & $\begin{array}{l}\text { Defenders are in a straight line and with no movement towards } \\
\text { the attacking line/attacker }\end{array}$ \\
\hline Arrow Head & $\begin{array}{l}\text { Defenders approach the attacking line in a triangle shape } \\
\text { formation, i.e. one defender is followed by other defenders } \\
\text { besides and behind him on each side }\end{array}$ \\
\hline Random & Defenders with no clear configuration or movement pattern \\
\hline \multicolumn{2}{|l|}{ Position of Tackler(Wheeler and Sayers, 2009) } \\
\hline Tight Forwards & Players 1-5 \\
\hline Loose Forwards & Players 6-8 \\
\hline Inside Backs & Players 9, 10, 12 \\
\hline Outside Backs & Players $11,13,14,15$ \\
\hline \multicolumn{2}{|l|}{ Position of Ball Carrier(Wheeler and Sayers, 2009) } \\
\hline Tight Forwards & Players 1-5 \\
\hline Loose Forwards & Players 6-8 \\
\hline Inside Backs & Players $9,10,12$ \\
\hline Outside Backs & Players $11,13,14,15$ \\
\hline
\end{tabular}

\subsection{Reliability}

For intra-coder reliability, two matches were coded (as per previous variables and physical component analysis). Then, 7 days later the same two matches were coded again to compare the results. Intra-class correlation coefficients for each time to contact point between the same 2 matches ranged from 0.86 - 0.94 for the ballcarrier, and 0.80-0.98 for the tackler. Typical error of measurement for each time to contact point between the same 2 matches ranged from $0.64-0.89 \mathrm{~m}^{-1}{ }^{-1}$ for the ballcarrier, and 0.77-1.89 m.s ${ }^{-1}$ for the tackler.

\subsection{Statistical Analyses}

One way analysis of variance was used to determine if there was a significant difference between the ball-carrier and tackler's mean velocity, as well as determine if pass number, match period, quality of defensive team, quality of attacking team, match status, defensive shape and movement, and ball-carrier and tackler position had an effect on the mean velocity of the ball-carrier and tackler. Repeated measures analysis of variance was used to determine if there was a significant difference between the ball-carrier and tackler's velocity at each time interval, as well as determine if pass number, match period, quality of defensive team, quality of attacking team, match status, defensive shape and movement, and ball-carrier and tackler position had an effect on the time to contact intervals of the ball-carrier and tackler. If significance was found, the Tukey Post-Hoc test was used. All data reported as mean \pm standard deviation, and all data was analysed using STATA 11.1 (StataCorp LP, USA) 


\section{Results}

The average velocity of each time to contact interval for the ball-carrier and tackler is shown in Figure 1. The mean velocity of the ball-carrier over the $0.5 \mathrm{~s}$ was $4.10 \pm 1.85 \mathrm{~m} . \mathrm{s}^{-1}$ and the mean velocity for the tackler was $5.19 \pm 3.22 \mathrm{~m} . \mathrm{s}^{-1}$, and this was statistically different $(\mathrm{p}<0.05)$.

\subsection{Interaction of Mean Velocity of Ball-Carrier and Defensive Factors}

Pass number had a significant effect on the mean velocity of the ball-carrier $(p<0.001)$. A far contact point was significantly faster than a close pass $(\mathrm{p}<0.001)$ as well as immediate contact $(\mathrm{p}<0.01)$. Similarly, a middle distance contact point was faster than a close pass $(p<0.01)$. The quality of the attacking team had an overall significant effect on the mean velocity of the ball-carrier $(p<0.001)$, with the top attacking side having a greater velocity than the bottom $(\mathrm{p}<0.01)$ and middle teams $(p<0.001)$. The location of the match and its effect on the ball-carrier's mean velocity was significant, the away team was faster than the home team $(\mathrm{p}<0.001)$. The position of the tackler significantly affected the ball-carrier's mean velocity $(p<0.05)$. When the tackler was a tight forward the ball-carrier was slower than if the tackler were an inside back $(\mathrm{p}<0.05)$.

\subsection{Interaction of Mean Velocity of the Tackler and Defensive Factors}

The match period (Q1-Q4) had an overall significant effect $(\mathrm{p}<0.05)$ on the tackler's mean velocity, with a significant decrease in mean velocity from Q2 to Q3 $(\mathrm{p}<0.05)$.

\subsection{Interaction of the approaching velocity measures of the tackler and ball- carrier and the defensive factors}

There were no significant effects of the defensive factors on the approaching velocities (velocity at each $0.1 \mathrm{~s}$ time interval for $0.5 \mathrm{~s}$ before contact) of the ballcarrier or the tackler except for the overall interaction between the quality of opposition and the ball-carrier's velocity interval points $(\mathrm{p}<0.05)$. The Tukey PostHoc test of this interaction however was significant at any specific time interval. 


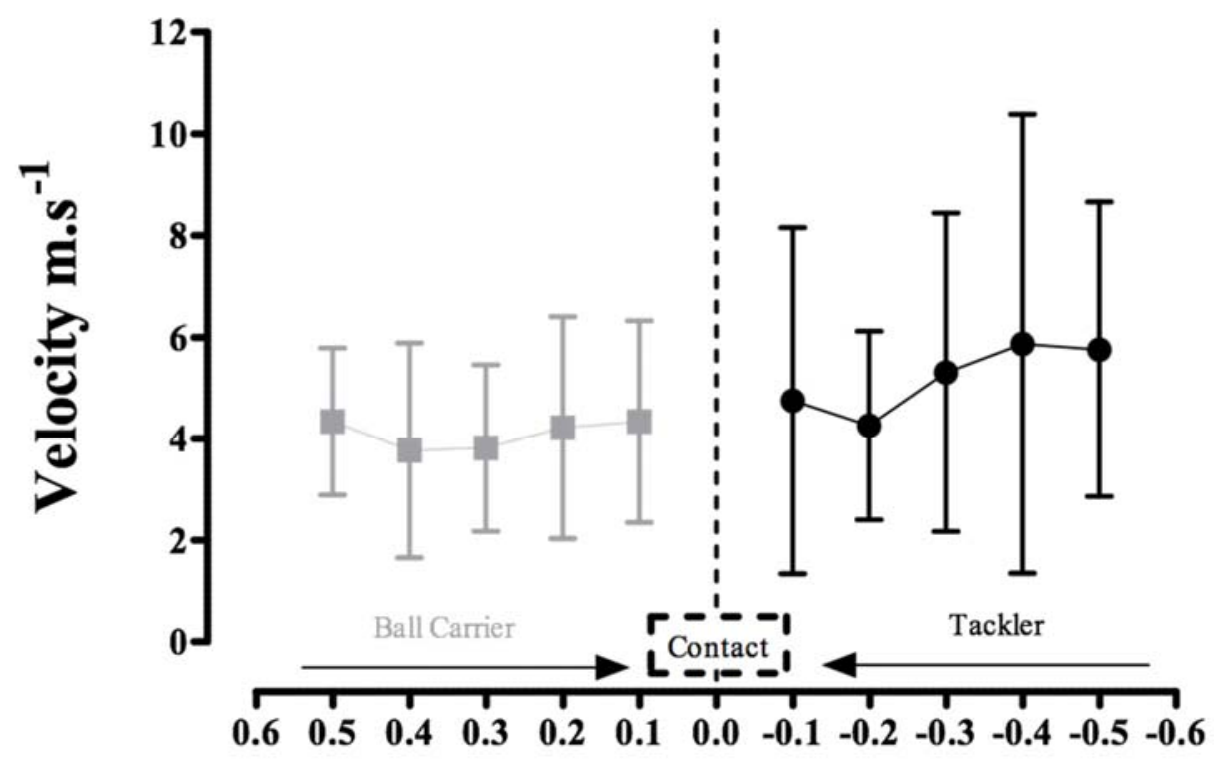

Time to Contact (s)

Figure 1: The average velocity of each time to contact interval for the ball-carrier and tackler ( $\mathrm{n}=12)$. Data reported as mean \pm standard deviation

\section{Discussion}

The front-on shoulder tackle is the most common occurring tackle in rugby union because if executed correctly, is the most safe and effective, however most often it is executed incorrectly and is responsible for the largest proportion of tackle-related injuries(Quarrie and Hopkins, 2008). The tackler and ball-carrier had a significantly different average velocity, with the tackler having a higher velocity than the ballcarrier. The average velocity of the ball-carrier $\left(4.10 \pm 1.85 \mathrm{~m} \cdot \mathrm{s}^{-1}\right)$ in this study, was comparable to a similar study on the same level of players $\left(4.8 \pm 2.9 \mathrm{~m} . \mathrm{s}^{-}\right.$ $\left.{ }^{1}\right)$ (Hendricks, Karpul, Nicolls, and Lambert, 2012). Likewise, for the tackler (5.19 $\pm 3.22 \mathrm{~m} . \mathrm{s}^{-1}$ found in this study vs $5.0 \pm 1.8 \mathrm{~m} . \mathrm{s}^{-1}$ found in Hendricks et al.(Hendricks, Karpul, Nicolls, and Lambert, 2012)).

The top teams, playing away matches, and playing the ball further away from the breakdown/set-piece were all associated with faster ball-carrier speeds into contact. Top teams having a higher velocity before contact may be an indicator of successful teams contact intensity during matches. Indeed, Wheeler and Sayers have shown significantly more tackle breaks occur when the ball-carrier has a good contact intensity(Wheeler and Sayers, 2009). With that said, player's physical properties alone are not sufficient to predict tackle contact success(Hendricks, Karpul, and 
Lambert, 2012). Ball-carrier's entered contact at higher velocities when the ball was passed further away from the breakdown or set piece. This is not surprising, considering more space is available further away from the breakdown/set-piece, allowing for higher running speeds to be reached. Tackler position had an effect on the ball-carrier's velocity into contact with the ball-carrier entering the contact slower when the tackler was a tight-forward. This finding may explain why looseforwards and tight forwards are more successful in contact than inside and outside backs when tackling(Hendricks, Matthews, Roode, and Lambert, 2014).

Ball-carriers velocity in contact was higher when playing away games. The influence playing home or away on the outcome of a match, and on game statistics in rugby union have been reported(Carron, Loughhead, and Bray, 2005; du Preez and Lambert, 2007; Morton, 2006; Thomas, Reeves, and Bell, 2008; Vaz, Carreras, and Kraak, 2012). Some studies show that playing home matches does relate to better performance, while other studies have found little difference in performance between home and away matches(Carron, Loughhead, and Bray, 2005; du Preez and Lambert, 2007; Morton, 2006; Thomas, Reeves, and Bell, 2008; Vaz, Carreras, and Kraak, 2012). Carron, Loughhead and Bray (2005)(Carron, Loughhead, and Bray, 2005) propose that match location may influence play through the crowd, learning/familiarity with the venue, travel and rule decisions. In explanation, away games may act as a motivator for running with a higher velocity into front-on soldier tackles as this may provoke the home crowd.

For the tackler, match period had a significant effect on velocity, with the tackler entering the tackle the slowest during the 3rd quarter (40-60mins into the match). In a recent meta-analysis, Williams et al. reported that the greatest incidence of injury was in the $3^{\text {rd }}$ quarter (40-60mins)(Williams, Trewartha, Kemp, and Stokes, 2013). The authors attributed this finding to possible incomplete warm up or reduced concentration following the half-time break. Also, poorer tackle technique and reduced force production during execution has been associated with player fatigue(Gabbett, 2008; Usman, McIntosh, and Frechede, 2011). Based on the findings of Usman et. al., Gabbett, Williams, the importance of physical conditioning for tackling has been highlighted(Gabbett, 2008; Usman, McIntosh, and Frechede, 2011; Williams, Trewartha, Kemp, and Stokes, 2013), and our finding of the effects of match period on tackler velocity supports this.

The purpose of this study was to investigate the factors that affect the velocity of the tackler and ball-carrier in shoulder tackles in the Super 14 rugby union competition. Although this was achieved, there are noteworthy limitations. Perhaps the most noteworthy limitation is the sample size. From the 15 matches, 763 instances where the defence and attack, and the resultant tackle could be identified were coded, however, only 12 tackles were valid for analysis. This relates to the specific criteria required for the 2-D analysis system. Also, the specific focus of front-on shoulder tackles may have also contracted the sample size. Nonetheless, the current study adds to literature on the physical components that may govern the tackle contact 
event(Hendricks, Karpul, and Lambert, 2012; Hendricks, Karpul, Nicolls, and Lambert, 2012).

In conclusion, the front-on shoulder tackle is the most common occurring tackle in rugby union because if executed correctly, is the most safe and effective(Quarrie and Hopkins, 2008). Factors that relate to the velocity at which ball-carrier's enter front-on shoulder tackles are quality of opposition, match location, pass number, and the position of the tackler. Only match period affected the velocity at which the tackler entered front-on shoulder tackles. This report furthers our understanding of rugby tackle governing dynamics before contact, which may have tackle training implications. 
1. Australian Rugby Union.(2008), Key points for the tackler and ball-carrier, Australian Rugby Union SmartRugby: Confidence in contact., 18-19.

2. Carron, A., Loughhead, T., and Bray, S.(2005), The home advantage in sport competitions: Courneya and Carron's (1992) conceptual framework a decade later., Journal of Sports Sciences, 23(4), 395-407.

3. du Preez, M and Lambert, M.(2007), Travel fatigue and home ground advantage in South African Super 12 rugby teams, South African Journal of Sports Medicine, 19(1), 20-22.

4. Duthie, G., Pyne, D., and Hooper, S.(2003), Applied physiology and game analysis of rugby union, Sports Medicine, 33(13), 973-991.

5. Fuller, C., Ashton, T., Brooks, J., Cancea, R., Hall, J., and Kemp, S.(2010), Injury risks associated with tackling in rugby union, British Journal of Sports Medicine, 44 159-167.

6. Gabbett, T.(2008), Influence of fatigue on tackling technique in rugby league players, Journal of Strength and Conditioning Research, 22(2), 625-632.

7. Garraway, W., Lee, A., Macleod, D., Telfer, J., Deary, I., and Murray, G.(1998), Factors influencing tackle injuries in rugby union football, British Journal of Sports Medicine, 33 37-41.

8. Headey, J., Brooks, J., and Kemp, SP.(2007), The epidemiology of shoulder injuries in English professional rugby union, American Journal of Sports Medicine, 35(9), 1537-1543.

9. Hendricks, S., Karpul, D., and Lambert, M.(2012), Momentum and kinetic energy during the tackle in rugby union.,

10. Hendricks, S., Karpul, D., Nicolls, F., and Lambert, M.(2012), Velocity and acceleration before contact in the tackle during rugby union matches, Journal of Sport Sciences, 30(12), 1215-1224.

11. Hendricks, S and Lambert, M.(2010), Tackling in rugby: coaching strategies for effective technique and injury prevention, International Journal of Sports Science and Coaching, 5(1), 117-131.

12. Hendricks, S., Matthews, B., Roode, B., and Lambert, M.(2014), Tackler characteristics associated with tackle performance in rugby union, European Journal of Sport Science, 1-10. 
13. Hendricks, S., Roode, B., Matthews, B., and Lambert, M.(2013), Defensive strategies in rugby union, Perceptual and Motor Skills: Exercise and Sport, 117(1), 1-23.

14. Kaplan, K., Goodwillie, A., Strauss, E., and Rosen, J.(2008), Rugby injuries: a review of concepts and current literature, Bulletin of the NYU Hospital for Joint Diseases, 66(2), 86-93.

15. McIntosh, A., Savage, T., McCrory, P., Frechede, B., and Wolfe, R.(2010), Tackle characteristics and injury in a cross section of rugby union football, American College If Sports Medicine, 977-984.

16. Morton, H.(2006), Home advantage in southern hemisphere rugby union: Nationaland International, Journal of Sport Sciences, 24(5), 495499.

17. New Zealand Rugby Union.(2007), Technique: the key factors in the tackle and taking the ball into contact., 12-14.

18. Quarrie, K and Hopkins, W.(2008), Tackle injuries in professional rugby union, American Journal of Sports Medicine, 36(9), 1705-1716.

19. Sayers, M and Washington-King, J.(2005), Characteristics of effective ball carries in super 12 rugby, International Journal of Performance Analysis in Sport, 5(3), 92-106.

20. Thomas, S., Reeves, C., and Bell, A.(2008), Home advantage in the Six Nations rugby union tournament, Perceptual and Motor Skills, 106 113-116.

21. Usman, J., McIntosh, A., and Frechede, B.(2011), An investigation of shoulder forces in active shoulder tackles in rugby union football., Journal of Science and Medicine in Sport, 14 547-552.

22. Vaz, L., Carreras, D., and Kraak, W.(2012), Analysis of the effect of alternating home and away field advantage during the Six Nations Rugby Championship, International Journal of Performance Analysis in Sport, 12 598-604.

23. Vaz, L., van Rooyen, M., and Sampaio, J.(2010), Rugby game-related statistics that discriminate between winning and losing teams in IRB and Super twelve close games, Journal of Sports Science and Medicine, 9 51-55.

24. Wheeler, K and Sayers, M.(2009), Contact skills predicting tackle-breaks in rugby union, International Journal of Sports Science and Coaching, 4(4), 535-544. 
25. Williams, S., Trewartha, G., Kemp, S., and Stokes, K.(2013), A metaanalysis of injuries in senior men's professional rugby union, Sports Medicine, 43(10), 1043-1055. 